\title{
INFLUENCIA DEL ÁCIDO ASCÓRBICO EN LA MADURACIÓN in vitro DE OVOCITOS DE PORCINO
}

\author{
Hugo Mauricio Gonzáles Molfino ${ }^{1}$
}

\begin{abstract}
RESUMEN
El presente tiene como objetivo esclarecer la influencia del ácido ascórbico durante la maduración de ovocitos de porcino in vitro. 845 complejos ovocito-cúmulo (COCs) seleccionados de ovarios de porcino, pre-púberes se incubaron en el medio de maduración (NSCU-23) que contenía ácido ascórbico en diferentes dosis: 0 (control), 250 y $500 \mu \mathrm{M}$ respectivamente. En todos los tratamientos se visualizó la expansión de las células del cúmulo al término del cultivo (44 horas). Se encontraron ovocitos maduros con corpúsculo polar en las diferentes concentraciones de ácido ascórbico, $71.8 \%$ en el control, $65.7 \%$ en el de 250 $\mu \mathrm{M}$ y $59.5 \%$ en el de $500 \mu \mathrm{M}$.

Estos resultados indicarían que el rol antioxidante del ácido ascórbico estaría encubierto por la presencia de antioxidantes como las superoxidismutasas y el glutation entre otros presentes en el fluido folicular de porcino.
\end{abstract}

Palabras Claves: Maduración de ovocitos, porcinos, acido ascórbico.

\section{SUMARY}

The objective of this study was to elucidate the role of ascorbic acid during in vitro porcine oocyte maturation. 845 Cumulus-oocyte complexes (COCs) were cultured for $44 \mathrm{~h}$ in NCSU 23 supplemented with cysteine, gonadotropins, $10 \%$ porcine follicular fluid, and ascorbic acid In all treatments, cumulus expansion was observed in cultures of 44 hours.

Were mature oocytes with polar corpuscle in the different ascorbic acid concentrations, $71,8 \%$ in the control, $65,7 \%$ in the of $250 \mu \mathrm{M}$ and $59,5 \%$ in the of $500 \mu \mathrm{M}$

These findings suggest that porcine follicular have a critical role in protecting oocytes against oxidative stress-induced through the enhancement of higher levels of superoxide dismutase and glutation content in follicular fluid.

Key words: Oocyte maturation, porcine, ascorbic acid.

\section{INTRODUCCIÓN}

Las hembras de los mamíferos tienen ovarios bifuncionales con función exocrina cuando liberan ovocitos y endocrina cuando producen hormonas que regulan el desarrollo folicular ovárico (Manikkan y et al., 2002). El conocimiento de estos procesos celulares es importante para comprender y establecer métodos eficientes que puedan usarse en la biotecnología reproductiva.

En el parénquima ovárico se localizan los complejos ovocito-cúmulo $\left(\mathrm{COC}_{\mathrm{s}}\right)$ formados por una delicada conexión entre las células del cúmulo y la membrana plasmática del ovocito (Moor et al., 1980), se pueden clasificar en relación a ciertas

\footnotetext{
${ }^{1}$ Laboratorio de Biología del Desarrollo. Facultad de Ciencias Biológicas. Universidad Ricardo Palma. e-mail: hgonzalesm@mail.urp.edu.pe
} 
características del cúmulo (compactación, transparencia y número de capas) así como del citoplasma (densidad y tamaño de gránulos). Esta conexión estructural y funcional es necesaria para que el proceso de maduración sea exitoso.

Los mecanismos de maduración del ovocito ocurren tanto en el núcleo como en el citoplasma. Las modificaciones visible en el núcleo son la condensación de la cromatina y la desintegración de la vesícula germinal (GVBD) cambios que permiten el reinicio de la meiosis hasta metafase II, cuya expresión citológica es la presencia del primer corpúsculo polar en la superficie del ovocito, estado en que el ovocito es ovulado. Por otro lado, las células del cúmulo no sólo son importantes para que el ovocito adquiera la competencia de desarrollo asociada con la maduración del citoplasma sino también que tienen un rol protector contra el daño que pueda causar el estrés oxidativo durante la maduración del ovocito. Tatemoto et al., (2000) sugieren que las células del cúmulo tienen un rol crítico en la protección de la apoptosis inducida por estrés oxidativo a través del incremento del contenido de glutatión en el ovocito. El glutatión es un tripeptido (???glutamincisteinglicina; GSH) que en las células de los mamíferos regula la síntesis, metabolismo y secreción de los antioxidantes celulares más importantes. Así mismo el GSH regula algunas funciones celulares esenciales como el mantenimiento de la integridad de las membranas celulares la síntesis de ADN, la modulación del plegamiento de las proteínas, el ensamblaje de los microtúbulos y también participa como coenzima en diversas reacciones enzimáticas (Meister, 1989). La competencia de desarrollo se incrementa después de fecundación in vitro en ovocitos de porcino madurados en presencia de acido ascórbico 2-O- áglucósido (AA-2G), sugiriendo que AA-2G previene el estrés oxidativo durante la maduración citoplasmática, permitiendo que el ovocito de porcino alcance competencia de desarrollo (Tatemoto et al., 2000).

Es de suma importancia que se cuente con protocolos experimentales que admitan el rol de los antioxidantes y de las especies oxígeno reactivas ROS durante la maduración y el desarrollo embrionario temprano en mamíferos. En el presente trabajo, usando indicadores citológicos (presencia del corpúsculo polar y expansión del cúmulo) se analiza la progresión de la maduración ovocitaria de porcino en el medio NCSU-23, al que se le adicionó ácido ascórbico en diferentes concentraciones.

\section{MATERIAL Y MÉTODOS}

\section{Recuperación y selección de ovocitos}

Se utilizó ovarios de porcino pre-púberes, provenientes de animales sacrificados para el consumo humano, los cuales fueron transportadas al laboratorio en un frasco térmico conteniendo una solución salina fisiológica $(0.9 \% \mathrm{NaCl})$ a $37^{\circ} \mathrm{C}$.

Para la recuperación de los complejos cúmulo-ovocito $\left(\mathrm{COC}_{\mathrm{s}}\right)$ se utilizó el método de aspiración folicular (Cheong y col., 2000). Utilizando una jeringa hipodérmica de 10 ml y una aguja de $21 \mathrm{G}$ (Gauge) se aspiró los folículos que oscilaban entre 4-6 mm colocándolos en un tubo de polipropileno (50 $\mathrm{ml}$ ) mantenido a una temperatura de $37^{\circ} \mathrm{C}$ en baño María. Luego de 10 minutos de reposo, se extrajo el sedimento del fondo del tubo llevándolo a las placas Petri, a las que se le agregó $25 \mathrm{mM}$ Hepes-buffer TCM-199 suplementado con $0.1 \%$ alcohol polivinílico y sulfato de gentamicina $50 \mu$ / $\mathrm{ml}$, sobre una platina temperada entre 30 $35^{\circ} \mathrm{C}$.

Para la selección de los COC se tomaron en cuenta indicadores morfológicos en el cúmulo: número de capas, compactación, y transparencia y en el citoplasma del ovocito: color (densidad) y tamaño de granúlos (Madison y col, 1992; Blondin y Sirard, 1993; Hazeleger y col., 1995; Hosoe y Shioya, 1997).

\section{Maduración in vitro de los COCs}

Para la maduración se utilizó el medio North Carolina State University 23 (NCSU-23; Petters \& Wells, 1993) suplementado con $0.57 \mathrm{mM}$ de cisteina, $10 \%$ fluido folicular, $10 \mathrm{IU} / \mathrm{ml}$ de gonadotropina corionica equina, $10 \mathrm{IU} / \mathrm{ml}$ de gonadotropina corionica humana y $50 \mu \mathrm{g} / \mathrm{ml}$ sulfato de gentamicina (Sigma). 
En una placa Falcon 3560 que contenía 100 ul de NCSU 23 cubierta con aceite mineral se colocaron entre 10 a 15 COCs para incubarlos por $20-24$ horas a $39^{\circ} \mathrm{C} ; 5 \%$ $\mathrm{CO}_{2}$; y $90 \%$ humedad. Transcurrido este tiempo, los ovocitos se pusieron en el medio NCSU 23 sin hormonas por un periodo adicional de 22 A 24 horas.

Al término del cultivo las células del cúmulo fueron separadas empleando un vortex por 4 minutos en una solución buffer fosfato PBS (Dulbecco's) sin $\mathrm{Ca}^{2+} \mathrm{y} \mathrm{Mg}^{2+}$ con hialuronidasa al $0,1 \%$ colocándolos después en 25 mM Hepes-buffered TCM-199. En este medio fueron seleccionados aquellos ovocitos maduros, que presentaron el primer corpúsculo polar los que fueron observados a través de una lupa estereoscópica 20x.

Los datos fueron procesados para encontrar el nivel de significancia mediante las pruebas de Student y Tukey.

\section{RESULTADOS}

Se seleccionaron 845 complejos ovocitocúmulo (COCs) que fueron obtenidos de ovarios de porcino pre-púberes y colocados aleatoriamente en el medio de maduración (NSCU-23), al que se le adicionó ácido ascórbico en diferentes dosis: 0 (control), 250 y $500 \mu \mathrm{M}$ respectivamente. En todos los tratamientos se visualizó la expansión de las células del cúmulo al término del cultivo (44 horas).

El porcentaje de ovocitos maduros que presentaron corpúsculo polar y citoplasma homogéneo fue de $71.8 \%$ para el control, $65.7 \%$ con $250 \mu \mathrm{M}$ y $59.5 \%$ con $500 \mu \mathrm{M}$ respectivamente (ver Tabla $\mathrm{N}^{\circ} 1$ )

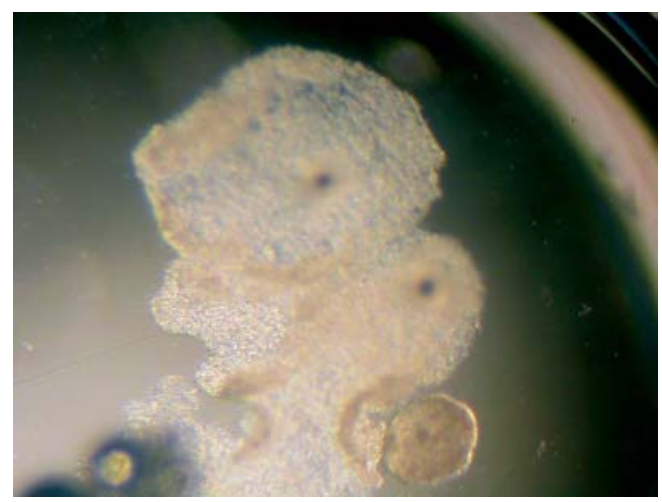

Fig 1: Expansión parcial de las células del cúmulo en cultivo de 24 horas de maduración (20 X)

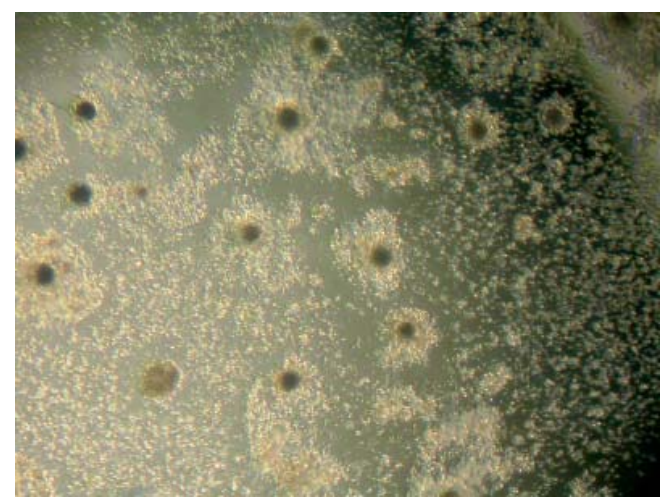

Fig 2: Expansión total de las células del cúmulo en cultivo de 44 horas de maduración $(20 \mathrm{X})$

Tabla $\mathrm{N}^{\circ}$ 1: Efecto del acido ascórbico en el medio de maduración de ovocitos porcino

\begin{tabular}{|c|c|c|}
\hline Tratamientos & No de Ovocitos (Replicaciones) & \% de Ovocitos Madurados \\
\hline Control (NCSU-23) & $255(4)$ & $71 \pm 1.41^{\mathrm{a}}$ \\
\hline NCSU-23 + 250 $\boldsymbol{\mu M}$ A.A & $285(4)$ & $62 \pm 2.83^{\mathrm{a}}$ \\
\hline NCSU-23 + 500 $\boldsymbol{\mu M A . A}$ & $305(4)$ & $59 \pm 1.41^{\mathrm{b}}$ \\
\hline
\end{tabular}

a,b Representa diferencia significativa p $<0.05$ 


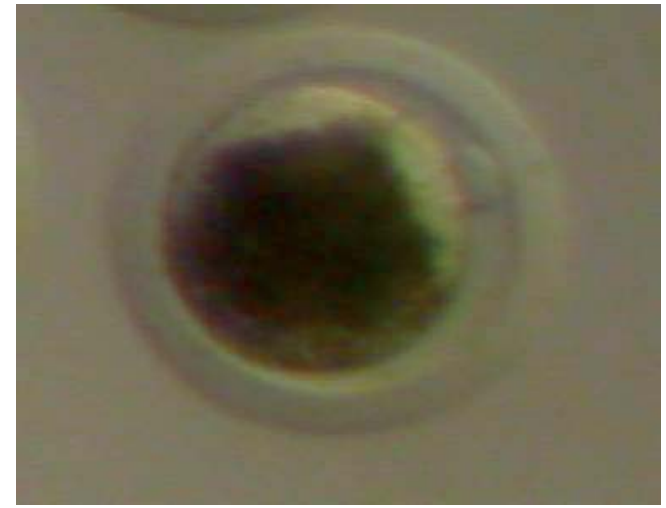

Fig.3: Ovocito maduro con presencia del corpúsculo polar en cultivos de 44 horas $(20 \mathrm{X})$

\section{DISCUSIÓN}

El desarrollo embrionario está influenciado por sucesos que ocurren durante la maduración de los ovocitos. Si bien es cierto que muchos ovocitos inmaduros son capaces de completar la meiosis in vitro, sólo un pequeño porcentaje de ellos adquieren una correcta competencia para continuar el desarrollo hasta el estado de blastocisto. Los ovocitos recolectados de ovarios procedentes de hembras sacrificadas para el consumo humano son una fuente extremadamente heterogénea en términos de calidad y competencia para el desarrollo,

El tamaño del folículo es un factor fundamental para que el ovocito adquiera competencia de desarrollo (Krisher, 2004), en esta investigación se usaron folículos que medían entre 3 a $5 \mathrm{~mm}$ de diámetro y presentaban irrigación superficial, con los que se logró una tasa de maduración relativamente alta en todos los tratamientos. Los COCs mantienen un acoplamiento mecánico y funcional entre la superficie de la membrana del ovocito con las de las células del cúmulo que permiten un flujo adecuado de sustancias en ambas direcciones durante el proceso de maduración. El flujo de sustancias se realizan a través de modificaciones de las proteínas de membrana denominados conexones (Canipari, 2000). Los COCs de 24 hrs de cultivo presentan una expansión mas compacta en relación a los cultivados por 44 hrs donde se muestra una expansión total de las células del cúmulo (Figs. 1y 2) que sería consecuencia de la perdida de acoplamiento celular durante el tiempo que dura la maduración in vitro. La expansión del cúmulo al término de la maduración también ha sido observada en cultivos de ovocitos de bovino y se explica que ocurre por la perdida de acoplamiento intercelular al desorganizarse los conexones, (Suzuki y et al., 2000). Las células del cúmulo secretarían ligandos para mantener el diploteno meiotico (Aktas y col. 1995) hasta que la actividad gonadotrópica induzca la despolarización de la membrana plasmática del ovocito, señal para el reinicio de la meiosis hasta metafase II (Mathioli y et al., 1990).La expresión citológica de que estos eventos moleculares ocurren, es la presencia del corpúsculo polar. En todos los tratamientos los cultivos entre 44 y 48 horas de incubación presentaron ovocitos con corpúsculos polares bien definidos (Fig.3)

Con respecto a la influencia del ácido ascórbico (AA) en la maduración de los ovocitos, se ha encontrado que $71 \%$ de COCs maduros en el medio NCSU-23 en relación al $62 \%$ y $59 \%$ hallados en los medios con $250 \mu \mathrm{M}$ y $500 \mu \mathrm{M}$ de AA respectivamente. En el medio NCSU-37 con ácido ascórbico 2-O- á-glucósido (AA$2 \mathrm{G}$ ) se han encontrado $86 \%$ de ovocitos de porcino maduros en el medio control, en relación a $82 \%$ y $77 \%$ que aparecen cuando se agrega al medio de cultivo 250 $\mu \mathrm{M}$ y $500 \mu \mathrm{M}$ de (AA) respectivamente (Tatemoto et al., 2000). El fluído folicular de porcino desempeña un papel crítico en la protección de los ovocitos de sustancias oxígeno reactivas mediante la activación de isoenzimas de superoxidismutasas las que inhiben la formación de radicales libre, mejorando considerablemente la maduración citoplásmica, importante, para la competencia de desarrollo posfecundación (Tatemoto et al., 2004). La proporción de ovocitos maduros encontrados $(p<0.05)$ en los tratamientos con y sin ácido ascórbico, se debería, de alguna manera, a la presencia de superoxidismutasas, y glutatión en el fluído folicular que se adicionó al medio NCSU23, que estarían encubriendo la posible 
actividad antioxidante del ácido ascórbico exógeno durante la maduración ovocitaria de porcino.

\section{LITERATURA CITADA}

AKTAS H., WHEELER M.B., FIRST N., LEIBFRIED-RUTELEDGE ML. 1995. Maintenance of meiotic arrest by increasing (cAMP)I may have physiological relevance in bovine oocyte. J. Reprod. Fertil 105 (2):23745.

BLONDIN P. \& A. SIRARD. 1995. Oocyte and follicular morphology as determining characteristics for developmental compertence in bovine oocyte. Mol Reprod Dev. 41, 54-62.

CANIPARI R. 2000. Oocyte-granulosa cell interations. Hum. Reprod. Update 6 (3):279-89.

CHEONG H.T., K. IKEDA, M.A. MARTINEZ., S. KATAGIRI. \& Y.TAKAHASHI. 2000. Development of resconstitud pig embryos by nuclear transfer of cultured cumulus cells. Reprod. Fertil. Dev. 12: 15-20.

HAZELEGER N.L., D.J. HILL., R.B. STUBBINGS. \& I.A. WATSON. 1995. Relationship of morphology and follicular fluid enviorment of bovine oocyte to their development potential in vitro. Theriogenology 43, 509-22.

HOSOE M. \& Y. SHIOYA. 1997. Distribution of cortical granules in bovine oocyte classified by cumulus complex. Zigote 5, 371-376.

KRISHER, RL. 2004. The effect of oocyte quality on development. J.Anim. Sci 82 suppl: $14-23$.

MADISON V., B. AVERY. \& T. GREVE. 1992. Selection of immature bovine oocytes for developmental potencial in vitro. Anim Reprod Sci 27, 1-11.

MANIKKAM M., Y. LI., B.M. MITCHELL., D.E. MASON \& L.C. FREEMAN. 2002. Potassium channel antagonist influence porcine granulose cell proliferation, differentiation and apoptosis. Biol Reprod. 67: 88-98.

MATHIOLI M., BARBONI B, BACCI ML, SEREN E. 1990. Maturation of pig oocytes: observationson membrane potential. Biol. Reprod. 43(2): 318-22.

MEISTER A. 1989. A brief history of GSH and survey of its metabolism and functions. In: Dolphin D., Avramovic O \& Poulson R (eds.) Glutathione: chemical, biochemical and medical aspects. Part A. New York, NY:Wiley pp: 1-48.

MOOR R.M., M.W. SMITH. \& R.M.C. DAWSON. 1980. Measurement of intercellular coupling between oocytes and cumulus cells using intracellular markers. Exp Cell Res: 126:15-29.

PETTERS R.M. \& K.D. WELLS. 1993. Culture of pig embryos. Journal of Reproduction and Fertility; Supplement 48: 61-73.

SIRARD, M. A. DUBUC, D. BOLAMBA, Y. ZHENG, K. COENEN. 1993. Follicle-oocyte-sperm interactions in vivo and in vitro in pigs. $J$ Reprod Fertil Suppl 48: 3-16.

SUZUKI H, JU J.C., YANG X. 2000 Surface ultrastructural alterations of bovine oocytes after parthenogenetic activation. Cloning 2:69-78.

TATEMOTO H., N. SAKURAI. \& N. MUTO. 2000. Protection of porcine oocytes against apoptotic cell death cuased by oxidative stress durin in vitro maturation: role of cumulus cells. Biol Reprod. 63: 805-810.

TATEMOTO H., MUTO N., SUNAGAWA I., SHINJOA, \& NAKADA T.2004. Protection of Porcine Oocytes Against Cell Damage Caused by Oxidative Stress During In Vitro Maturation: Role of Superoxide Dismutase Activity in Porcine Follicular Fluid. Biol Reprod. 71: 1150-115. 